\title{
Bargaining within the Supply Chain and Its Implications in an Industry
}

\author{
Opher Baron, Oded Berman; Desheng $\mathrm{Wu}^{\ddagger}$
}

Our main objective is to investigate the influence of the bargaining power within a chain on its industry. As a building block, we first discuss the implications of bargaining within a single chain by considering an asymmetric Nash bargaining on the wholesale price (BW). We show that both Manufacturer Stackelberg (MS) and VI strategies are special cases of the BW contract. We then develop the Nash equilibrium in an industry with two supply chains that use BW. We identify the profit-maximizing (coordinating) bargaining power within this industry. We show that when a chain is not monopolistic, Vertical Integration (VI) does not coordinate the chain and that the MS contract, where the manufacturer has all the bargaining power, is coordinating when competition is intense. Our results lead to several predictions supported by empirical findings, such as that in competitive industries chains will work "close to" the MS contract.

Key words: Bargaining Power, Competition, Supply Chain Coordination.

\section{Introduction}

The two most common models of supply chain strategies are Vertical Integration (VI) and Manufacturer Stackelberg (MS). In a VI supply chain production quantity and retail price are chosen as if the wholesale price is identical to the production cost. In a supply chain that uses an MS strategy the manufacturer and retailer operate in a non-cooperative environment; the manufacturer is a leader posting a take-it-or-leave-it wholesale price and the retailer is a

\footnotetext{
*Opher.Baron@Rotman.utoronto.ca. The Rotman School of Management, the University of Toronto, Toronto, Canada

${ }^{\dagger}$ Berman@Rotman.utoronto.ca. The Rotman School of Management, the University of Toronto, Toronto, Canada

‡Desheng Wu, dash@risklab.ca RiskLab, Univeristy of Toronto and Reykjavik University.
} 
follower that maximizes its profits given this wholesale price. However, in many supply chains a more natural way of "doing business" is that after the manufacturer posts its wholesale price, the retailer comes back with a (lower) wholesale price offer; thus, firms bargain on the wholesale price. The results of this bargaining process depend, of course, on the bargaining power of the firms. Several examples for bargaining are given in Iyer and Villas-Boas (2003) and in Ertek and Griffin (2002). The bargaining power of large retailers such as Wal-Mart is discussed in Dukes et al. (2006). Draganska et al. (2010) observe that bargaining power varies significantly across manufacturers and retailers through an investigation of the German ground coffee industry. For example, a manufacturer with top-selling brand, Jacobs, has average bargaining power and the biggest retailer, Metro, does not have the highest overall bargaining power. A natural question arises: among various bargaining powers available to manufacturers and retailers, what are the ones that maximize the profit of the supply chain?

In this paper we examine the effect of bargaining within competing supply chains on their prices, quantities, and resulting profits using the Nash bargaining model. Because different firms in the supply chain may have different bargaining bargaining powers (e.g., Wal-Mart), we believe that capturing asymmetry in the bargaining procedure within a supply chain is essential. Therefore, we consider asymmetric Nash bargaining models.

The premise of this paper is to improve the understanding of supply chain strategy and the effect of the practice of bargaining on the equilibrium in an industry with several supply chains. We establish a collection of results that jointly achieve this premise. We would like to emphasize that the paper is descriptive rather than prescriptive. Thus, the emphasis is on describing the possible reasonable outcomes when bargaining is prevalent rather than prescribing what companies should do given this practice. We next discuss this collection of results and their implications. For convenience we highlight them with capital letters in parenthesis.

We denote the strategies of firms bargaining over the wholesale price as $\mathrm{BW}(\alpha)$, where $\alpha$ is the bargaining power of the manufacturer $(1-\alpha$ is that of the retailer $)$. The asymmetry in the bargaining power allows us to show the following result which we name $(\mathrm{A})$ : both the MS and the VI strategies are special cases of the BW $(\alpha)$ strategy. (The equivalence of MS to a bargaining process was also discussed by Iyer and Villas-Boas (2003).)

Our discussion of a coordinated supply chain makes an important distinction. We first define the contract space the chain faces as the different contracts under which the supply 
chain may operate such as bargaining or MS. The contract space includes all the actions that each player in the chain can take. Then, we use the term coordinated supply chain to represent a supply chain that maximizes its profit given the market conditions and contract space it faces. That is, in a coordinated supply chain, the choices made by each party in the chain maximize the profit of the entire chain rather than their individual profits. This maximization considers both the best response of the competition, when such exists, and the contract space.

This definition of a coordinated supply chain may contrast the common notion that the centralized, VI, chain is coordinated. Indeed, in a VI chain the choices made by the single decision maker aim at maximizing the profit of the entire chain. However, in some settings such choices do not guarantee optimality of the chain's profit, because several decision makers can make decisions that are not credible when a single decision maker takes them.

The fact that several decision makers may improve the chain's profit, in comparison to a single decision maker, has been established in the seminal work of McGuire and Staelin (1983) who studied an industry with two competing supply chains. They consider a Bertrand (i.e., price) competition between two suppliers each selling through an independent retailer and discuss the effect of the level of product substitutability on optimal distribution channels. They consider VI and MS chains and show that when competition is intense it is an equilibrium with higher profits for both chains when they use MS rather than VI contracts.

McGuire and Staelin (1983)'s model is stylized and ignores the practice of bargaining. In fact, in the 25 years commentary on their original work, Staelin (2008) writes "I believe we need to develop a better approach for capturing the fact that retailers exhibit "power" (i.e., the retailer limits, but does not control, the options of the upstream channel members). Perhaps we should think in terms of a bargaining framework." Indeed, by adding bargaining to their model we establish, Theorems 2-3, that (B): in an industry with two competing supply chains VI never maximizes the chain's profits and therefore VI chains are not coordinated in these settings. This result in our clear settings where bargaining is considered supports Bonanno and Vickers (1988) and Coughlan and Wernerfelt (1989)'s similar conclusion (that was derived in a somewhat contrived settings). Result (B) contrasts a large stream of literature suggesting supply chain coordination contracts that induce the chain to act as if it is VI. Supply chains that are a part of an oligopoly who use such contracts are not really coordinated - they leave money on the table. 
McGuire and Staelin (1983) give examples of industries with several supply chains. Thus, the result that VI does not coordinate the SC in such settings is not relevant only in a purely theoretical context. Below, we consider two additional examples: that of the gasoline industry in the city of Vancouver and that of the German ground coffee industry (mentioned earlier).

We further show that when competition is increasing, so does the manufacturer power necessary to coordinate the chains. This analysis leads to an additional important observation (C): when competition is intense, the standard MS contract used in practice is efficient in the sense that it coordinates the chains. This is in a sharp contrast to the problematic MS contract in the monopoly settings (Shen et al. 2013; Choi et al., 2008). Together with result (B) that VI chains in an industry are never coordinated, our results show that, when considering competition, much of the common sense developed in the operations literature for monopolistic markets is misleading.

Our theory predicts that (i) the amount of money left on the table when the chains are not coordinated is increasing with the intensity of the competition (see e.g., Figure 2(a) discussed later). This prediction agrees with empirical evidence from the gasoline industry in Vancouver: Slade (1998) showed that in gas stations facing a more intense competition, the potential improvement in profit when using the standard MS contract, which is coordinating given result $(\mathrm{C})$, is higher. We further predict that (ii) the equilibrium in mature industries with intense competition that are dominated by a small number of chains will only include chains that work with a contract that is close to the coordinating contract, i.e., the standard MS contract. This is true because when competition is intense, coordinated chains may operate even when other competitors go out of business. We compare this prediction with the empirical results for the gasoline industry in Vancouver where different levels of the intensity of competition can be characterized. Indeed, in this industry stores that face more intense competition work closer to MS settings and Slade (1988) shows that such stores could maximize profit, i.e., coordinate, by shifting to the MS contract. Finally, we predict that (iii) as the difference between the bargaining power within the chain to the efficient bargaining power increases, the amount of money left on the table increases. The empirical observations from Draganska et al. (2010) that consider the German ground coffee industry agree with this prediction.

The paper continues as follows. In the next section we discuss the relevant literature and 
review two background models. Section 3 discusses Nash bargaining over the wholesale price. The main result of section 3 is that for given (exogenous) power structures (represented through the bargaining powers, $\alpha_{i}$ and $\alpha_{j}$ ), there is a corresponding wholesale price. In Section 4 we investigate bargaining over the wholesale price in the McGuire and Staelin (1983) stylized industry. The thrust of section 4 is to take the $\alpha$ 's and the wholesale prices, w's, as given and then to find the equilibrium prices and profits in the competitive setting. (The equilibrium wholesale prices are not optimized jointly - the wholesale prices are directly linked to the exogenous $\alpha$ 's and then the retail prices are determined taking the wholesale prices as given.) In Section 5 we investigate the efficient bargaining power and its benefit. This Section discusses whether the given (exogenous) bargaining powers $\left(\alpha_{i}\right.$ and $\left.\alpha_{j}\right)$ results in a coordinated supply chains, or whether a different bargaining power could be better. While, as a manager, it may not be possible to change the bargaining power, the paper provides insights into why some bargaining power structures have evolved as most prominent in various industries. Specifically, for a different levels of competition, Theorem 2 gives the resulting Nash equilibrium assuming that the bargaining power in both supply chains is the most effective one (i.e., both chains happen to have the coordinating bargain power). We summarize the paper and discuss its managerial insights in Section 6. All proofs are included in Appendix I.

\section{Literature Review and Relevant Background}

Here we review relevant literature and two background models: a model for bargaining between two players, based on Nash (1950) and Binmore et al. (1986), and a model for competition between two supply chains based on McGuire and Staelin (1983).

\subsection{Literature Review}

Several papers addressing bargaining in the supply chain are relevant to our work. Ertek and Griffin (2002) investigate the effect of bargaining on the supply chain when either the manufacturer or the retailer has dominant power. Dukes et al. (2006) consider channel bargaining with retailer asymmetry. Similar to us they use the Nash bargaining solution to model the negotiation. However, they model the source for the asymmetry between retailers as different outside options (or threat points). Thus, they restricted their attention to symmetric bargaining power between the manufacturer and each of the retailers. In contrast, 
and in line with the use of the Nash bargaining product with asymmetry as explained in Binmore et al. (1986), we consider the outside options independently of the bargaining power within the chain. Nair et al. (2011) shows that relative bargaining power in the supplierbuyer relationship can be adjusted by means of their relative endowment of critical resources. Therefore, a behavioral experiment can be designed to examine the dynamic evolution of bargaining power.

Gurnani and Shi (2006) use a Nash bargaining model to address incentive compatibility in a single supply chain where both the buyer and seller have asymmetric information on supply delivery. Nagarajan and Bassok (2008) consider a sequential bargaining process and the influence of the bargaining power on the optimal structure of coalitions of suppliers facing a single assembler. Their model is also mentioned in the survey by Nagarajan and Sosic (2008). All of the literature surveyed there ignore competition between supply chains. In contrast to this literature, we also consider an industry with competing supply chains and characterize the profit-maximizing bargaining power structure in the industry.

All of the above papers ignore bargaining within an industry. Moreover, none of these papers allows for a continuum of bargaining power within the supply chain, as we do.

In monopolistic markets with a single chain a VI supply chain is coordinated, e.g., Bernstein and Federgruen (2005) and Cachon (2003). Consequently, several supply chain coordination mechanisms that induce the chain to act as if it is VI were investigated, e.g., two part tariff, Ingene and Parry (1995), buy back, Pasternack (1985), quantity flexibility, Tsay (1999) and Weng (1995), and revenue sharing, Cachon and Lariviere (2005), see also Lariviere and Porteus (2001). For a survey of this literature that typically ignores competition see Cachon (2003).

Two competing supply chains are investigated in the seminal work of McGuire and Staelin (1983) who established that when products are highly substitutable the MS supply chain Nash equilibrium is preferable by both manufacturers. Coughlan (1985) extends this research and applies it to the electrical industry and Moorthy (1988) further explains why MS chains can lead to higher profits for the manufacturer and the entire chains. In the operations literature, Wu and Chen (2003) consider a Cournot (i.e., quantity) competition of a duopoly where each chain includes a single manufacturer and two retailers facing a newsvendor demand. The common features of these papers in contrast to ours are that they do not consider bargaining and only focus on competing products whereas we allow both 
competing and complementing ones.

Lin and Kong (2002) consider the operational actions of firms in a duopoly when firms use strategies of VI, MS, and symmetric Nash bargaining over the wholesale price. They show that symmetric Nash bargaining can lead to higher supply chain profits than a VI one with a single profit division between the manufacturer and the retailer. In contrast we consider asymmetric bargaining power. Since we prove that both the VI and MS strategies are special cases of the $\mathrm{BW}(\alpha)$ strategy, the comparison of these cases in Lin and Kong (2002) is less viable. Moreover, we also characterize the efficient equilibrium in the industry.

Liu and Tyagi (2011) employ Hoteling model to study the effects of upward channel decentralization where competing firms can outsource their production to upstream suppliers without any production cost savings. They show that downstream firms can still benefit from upward channel decentralization provided their product positioning is endogenous. Feng and Lu (2012) study competing manufacturers' low cost outsourcing behavior in a multiunit bilateral bargaining framework. They find that manufacturers with low bargaining power are more likely to lose from outsourcing (even if they are positioned as low cost providers).

Another interesting and relevant paper is Balasubramanian and Bhardwaj (2004). They presented a duopoly with competition over both price and quality. They introduced two tactical approaches for managing the firm. In the first, a single decision maker within the firm dictates both price and quality, this can be thought of as a VI firm in our model; and in the second approach the marketing and operations department within the firm have conflicting incentives, these departments are similar to the retailer and manufacturer in our model. For firms with such a conflict, the quality is influenced by the marketing department and the price depends on the cost of that quality as incurred by the operations department and the conflict is being solved using a Nash bargaining model. Similar to our results, Balasubramanian and Bhardwaj (2004) show that firms that use bargaining may be better off than firms with a single decision maker. Moreover, they show that when the firms' owners can choose between both approaches they will gain a higher profit in the equilibrium where both firms bargain.

Finally, there are two empirical papers that we use to contrast our results with. The first is Slade (1998) who analyzed the gasoline industry in Vancouver. In this industry several major oil companies sell their oil directly to the end consumer under their brand name. These companies control about $88 \%$ of the market. Therefore, this market can be thought 
of as a mature industry with an oligopolistic competition. She investigated the potential improvement in profit of gas stations facing different intensity of competition and showed that stores facing intense competition could coordinate by shifting to the MS contract. The second is Draganska et al. (2010) whose empirical investigation of bargaining power is quite sophisticated. They consider the German coffee market where several retailers and manufacturers are competing (in contrast to out competing between supply chains). The model they proposed focuses on three factors influencing the bargaining power, namely, store size, store brand, and service level. They suggested detailed models for the demand and for the retail and wholesale prices. They used their model and analysis to empirically support that the bargaining power influences the total profitability of a product (or size of the pie), and that in some cases a lower bargaining power for one of the participant in the chain implies a higher profitability for this player. The reason behind this improved profitability is that the reduced power increases the total profitability of the channel (i.e., the pie). Our stylized model provides a theoretical justification for the empirical observation made in both papers.

\subsection{Nash Bargaining}

Binmore et al. (1986) review two strategic bargaining models a strategic bargaining model with time preferences or with exogenous risk of breakdown. They also give a condition for both models to have a unique perfect equilibrium that is identical to a properly defined Nash bargaining model. The Nash bargaining model, presented by Nash (1950) and discussed by Kalai and Smordinsky (1975), can be formulated as a Nash bargaining product, e.g., Binmore et al. (1986). We assume that both the manufacturer and the retailer are profit maximizers and that they bargain over the wholesale price, $\theta$. We denote the bargaining power of the manufacturer by $\alpha \in[0,1]$, that is exogenously given; and thus $1-\alpha$ is the bargaining power of the retailer. Then, the cases $\alpha=0$ and $\alpha=1$ allow the retailer and manufacturer, respectively, to dictate the choice of $\theta$.

We denote the utilities of the retailer, manufacturer, and supply chain, respectively by $\pi^{R}, \pi^{M}$, and $\pi^{S C}$, all depend on $\theta$. We let $\widetilde{\Phi}(\theta)$ be the Nash bargaining product, $f^{M}, f^{R}$ be the manufacturer's and retailer's threat points, respectively. Then, the Nash bargaining 
product model is ${ }^{1}$ :

$$
\operatorname{Max}_{\theta}\{\widetilde{\Phi}(\theta)\}=\operatorname{Max}_{\theta}\left\{\left(\pi^{M}-f^{M}\right)^{\alpha}\left(\pi^{R}-f^{R}\right)^{1-\alpha}\right\} .
$$

We consider firms' utilities as their profits, as is common in the modeling of risk neutral firms. Binmore et al. (1986) state that the threat points should reflect the status quo between the negotiating parties rather than outside options. For the model with time preferences this status quo is the utility gained by the parties during their negotiation. For the model with exogenous risk of breakdown this status quo is the utility gained by the parties if the bargaining breaks down. We will explicitly discuss the values for the threat points when applying the Nash bargaining model. Binmore et al. (1986) suggest that asymmetry in bargaining power, can be attributed to asymmetries in: preferences, threat points, beliefs on the environment, and the bargaining procedure. They note that the first two asymmetries are captured by the model and that the asymmetry caused by the last two should be captured through differences in the bargaining power, $\alpha$. We apply the asymmetric Nash bargaining framework, without further investigating the causes to this asymmetry.

\subsection{A Stylized Industry Model of Competition}

McGuire and Staelin (1983) focus on two supply chains that face a certain additive demand as in Mills (1959). Let $p_{i}^{\prime}$ and $q_{i}^{\prime}$ be the price and quantity, for chain $i=1,2$. The simplified model in McGuire and Staelin (1983) provides a base model for modeling relations between prices and quantities as well as firm profits in the market:

$$
\begin{aligned}
q_{i} & =1-p_{i}+b p_{j}, & i=1,2 ; & j=3-i, \\
\pi_{i}^{S C} & =p_{i} q_{i} & & i=1,2, \\
\pi_{i}^{R} & =\left(p_{i}-w_{i}\right) q_{i}, & & i=1,2, \\
\pi_{i}^{M} & =w_{i} q_{i}, & & \text { and } \\
& & & =1,2 .
\end{aligned}
$$

where $b$ represents the substitution level between products. Thus, $b=0$ implies that the chains are independent of each other while $b=1$ implies that the products are not differentiable. In the sequel we consider two supply chains with demand and profits as given in (2)

\footnotetext{
${ }^{1}$ An additional requirement of the Nash bargaining approach is to have individual rationality, i.e., that the optimal profit for each firm is at least as high as when they do not bargain, e.g., Iyer and Villas-Boas (2003) and Assumption 4 of Kalai and Smordinsky (1975).
} 
to (5). Similar to Gupta and Loulou (1998), we note that larger $b$ means larger total demand in the industry. Thus, one should be careful when comparing outcomes for different $b$-values. McGuire and Staelin (1983) show that when $b \geq 0.931$; there is a Nash equilibrium where both supply chains use MS and $\pi^{M}$ of the MS supply chain is larger than $\pi^{S C}$ when both supply chains are VI. Moreover, they show that for any $b \in[0,1]$ there is a Nash equilibrium in which both supply chains use VI.

\section{Nash Bargaining in a Single Chain}

In the 25 years commentary on McGuire and Staelin (1983), Staelin (2008) writes "I believe we need to develop a better approach for capturing the fact that retailers exhibit "power" (i.e., the retailer limits, but does not control, the options of the upstream channel members). Perhaps we should think in terms of a bargaining framework." To study this and as a building block to studying bargaining in the presence of competition, in this section we consider bargaining over the wholesale price. We discuss the implications of this bargaining model. Note that a single chain can be thought of as the industry described by (2) - (5) with $b=0$.

\subsection{Bargaining on the Wholesale Price}

Here, we formulate the Bargaining over the Wholesale Price (BW) strategy between the manufacturer and the retailer within a single supply chain. This contract extends the standard "take it or leave it" (MS) model to settings in which the manufacturer and retailer bargain over the wholesale price. We compare the equilibrium results within the chain with those of the VI and MS strategies.

For a chain that uses a BW strategy we consider the following sequence of events: the

manufacturer and retailer bargain on the wholesale price, $w \geq 0$, and once they agree, the retailer orders its desired quantity, $q \geq 0$ (which is fully produced and delivered by the manufacturer). Then, the retailer chooses price $p \geq 0$ and sales take place.

For reasons that will become apparent soon, we model a VI supply chain as a chain owned by the retailer; then, the manufacturing cost is the wholesale price that the retailer faces. Thus, in a VI chain the retailer chooses the desired quantity and the retail price, and then sales take place. With these decisions, in a supply chain with a VI strategy all the profit is obtained by the retailer. Of course, if the chain uses a coordination contract that induces it 
to act as if it is VI, the profit will be shared between the retailer and the manufacturer. (In Wu and Chen (2003), a buy back contract results in equilibrium that is not VI. However, we believe that this is a result of the information asymmetry considered there.)

In a supply chain with an MS strategy the manufacturer first chooses the wholesale price to maximize its profits, knowing how the retailer will respond. Then, the retailer orders its desired quantity, $q$, and finally, the retailer chooses the retail price, $p$, and sales take place.

Using the bargaining procedures discussed in Section 2, we express the Nash bargaining product, $\widetilde{\Phi}(w)$, for a manufacturer and a retailer bargaining over the wholesale price, $w$, as:

$$
\operatorname{Max}_{w}\{\widetilde{\Phi}(w)\}=\operatorname{Max}_{w}\left\{\left(\pi^{M}-f^{M}\right)^{\alpha}\left(\pi^{R}-f^{R}\right)^{1-\alpha}\right\} .
$$

For simplicity of the exposition, we assume that the status quo during the negotiation results in a profit 0 to the firms, and also that the status quo if the firms never reach an agreement is a profit 0 . Thus, we choose $f^{M}=f^{R}=0$ to reflect the status quo.

In our model, the individual rationality requirement is relevant only when $\alpha=0$ and we enforce it by requiring that the feasible set for $w$ is $w \geq 0$. Thus, the feasible set for $w$ is convex.

The $\mathrm{BW}(\alpha)$ with, $\Phi(w)$, the adjusted Nash bargaining product, then becomes:

$$
\operatorname{Max}_{w \geq 0}\{\Phi(w)\}=\operatorname{Max}_{w}\left\{\left(\pi^{M}\right)^{\alpha}\left(\pi^{R}\right)^{1-\alpha}\right\}=\operatorname{Max}_{w}\left\{q(w)^{\alpha}(p-w)^{1-\alpha}\right\} .
$$

We show:

Theorem 1. The $B W(1)$ model is equivalent to the $M S$ model and the $B W(0)$ model is equivalent to the VI model.

The results of Theorem 1 are widely applicable and not very surprising. In principle, when the manufacturer is the dominant player $(\alpha=1)$, she will choose to maximize her profit by charging the wholesale price in accordance with the MS outcome. Similarly, when the retailer is the dominant player $(\alpha=0)$, he will choose the lowest feasible wholesale price (equals to the marginal cost).

There are settings when Theorem 1 is not applicable. One example is Misra and Mohanty (2006), who model a bargaining game with a single retailer and multiple manufacturers, and show that the MS game is a special case of their setup where the retail price is set after bargaining has taken place. The other example is in Proposition 4 of Iyer and Villas-Boas (2003) where the MS solution arises when the bargaining power of the manufacturer is 
medium. The reason for this difference is that in their settings, when products are not completely specifiable (there is some uncertainty in their quality), additional manufacturer power may reduce the chain's profit; then the manufacturer's profit can decrease with an increase in her bargaining power. (See their discussion following Proposition 3.) Another example is the case when demand is uncertain and there is a limit on the manufacturer's capacity. Such a case may lead to the result that $B W(0)$ is not equivalent to VI. Note that Iyer and Villas-Boas (2003) also establish that when the retailer has all the bargaining power (equivalent to $B W(0)$ ) the supply chain performs as a VI. However, their result requires additional conditions to ours, e.g., non specifiable products. They also show that a greater retailer power helps to coordinate their monopolistic chain. Our model leads to a sharper conclusion: when the manufacturer has no bargaining power, the chain acts as if it is VI.

\section{Bargaining in the Stylized Industry}

Below we consider the stylized industry with two supply chains described in Section 2 . Each supply chain has a given $\alpha_{i} \in[0,1]$, representing the relative market power of its manufacturer. Given these $\alpha_{i}$ the firms in each chain make their operational decisions in the same sequence of events discussed for the single bargaining supply chain: each chain $i$ bargain over its wholesale price $w_{i} \geq 0$, then the retailers order a quantity $q_{i} \geq 0$, which is fully produced and delivered by the manufacturer. Then, both retailers simultaneously choose price $p_{i} \geq 0$ to maximize their profits. Thus, as in McGuire and Staelin (1983) retailers face a Bertrand (price) competition. Below we find equilibrium decisions for all participants in the industry and the corresponding profits. While the derivation is simple it is required for the analysis in subsequent sections.

We assume that neither of the supply chains has a leader position in its prices or quantity decisions and that all the information, including the $\alpha$ 's, is common knowledge. While in the original model of McGuire and Staelin (1983) both supply chains are symmetric up to their market share, we allow asymmetry between the chains by assuming a different manufacturer bargaining power, $\alpha$. Moreover, while McGuire and Staelin (1983) assume in their model that $b \in[0,1]$, we allow $b \in(-1,1)$ where negative values of $b$ imply that the products are complements. Coordination of chains with complementary products may increase both chains' profits. 
We search the subgame-perfect Nash channel equilibrium for the decisions of the parties within the chain. To find this equilibrium, we require the Nash equilibrium profits of each chain and its participants. We find the latter using backward induction starting at the Nash equilibrium strategies for the quantity and price decisions in each chain for the $B W\left(\alpha_{1}\right) B W\left(\alpha_{2}\right)$ model.

Observe that with no uncertainty, price is chosen such that there will be no leftovers. Thus, the demand faced by the $i^{t h}$ chain, $d_{i}=q_{i}$. Then, for the supply chains that are not VI, i.e., for $\operatorname{BW}(\alpha)$ with $\alpha>0$, given a wholesale price $w$ we have:

$$
\begin{aligned}
\pi_{i}^{R} & =\left(p_{i}-w_{i}\right) q_{i}=\left(p_{i}-w_{i}\right) d_{i}, \\
& =\left(p_{i}-w_{i}\right)\left(1-p_{i}+b p_{j}\right), \quad i=1,2 \quad j=3-i,
\end{aligned}
$$

where the last equality follows from (2) and that $q_{i}=d_{i}$. As in (4.27) and (4.28) of McGuire and Staelin (1983), the Nash equilibrium retail prices, as functions of $w_{i}$ and $w_{j}$ are

$$
p_{i}=\frac{2+b+b w_{j}+2 w_{i}}{4-b^{2}} \quad i=1,2 \quad j=3-i,
$$

and the Nash equilibrium order quantities are

$$
q_{i}=p_{i}-w_{i}=\frac{2+b+b w_{j}+\left(b^{2}-2\right) w_{i}}{4-b^{2}} \quad i=1,2 \quad j=3-i .
$$

Substituting the optimal retail price and order quantity to the Nash bargaining product (7) gives:

$$
\begin{aligned}
& \operatorname{Max}_{w_{i}}\left(\Phi_{i}\left(w_{i}\right)\right) \\
= & \operatorname{Max}_{w_{i}}\left\{\left(\frac{2+b+b w_{j}+\left(b^{2}-2\right) w_{i}}{4-b^{2}}\right)\left(w_{i}\right)^{\alpha_{i}}\left(\frac{2+b+b w_{j}+\left(b^{2}-2\right) w_{i}}{4-b^{2}}\right)^{1-\alpha_{i}}\right\} .
\end{aligned}
$$

The optimal wholesale price, $w_{i}$, profit for the supply chains, $\pi_{i}^{S C}\left(\alpha_{i}, \alpha_{j}\right)$, and manufacturer profits are given in Appendix I.

\section{Efficient Bargaining Power}

We next investigate the effect of different bargaining powers within the chains on the industry. From our definition a coordinated supply chain represents a chain that maximizes its profit given the market conditions and contract space it uses. Similarly, we define the efficient bargaining power as the profit-maximizing bargaining power for the chain given the market 
conditions it faces and the contract space of the other chain in the industry. The possible contracts within the contract space are exogenously given. Note that bargaining assumes that the chain uses a $B W(\alpha)$ contract, thus only the contracts possible for the other chain in the industry are relevant in the above definition. Therefore, the efficient bargaining power coordinates the chain.

While we do not assume that firms have the ability to choose the efficient bargaining power in order to coordinate, there are three explanations why the bargaining power of a supply chain would be the efficient one. First, in mature industries the advantage (higher profit) of chains with the efficient bargaining power may allow them to operate while competitors go out of business. Thus, the equilibrium in mature industries with intense competition should include only chains with a bargaining power close to the efficient one. The second explanation is that the participants in the chain first bargain over sharing the extra profit generated from coordination and then bargain over the wholesale price. That is, maximizing the chain's profit is beneficial to all participants in the chain. This explanation agrees with the discussion of the factors leading to asymmetry in the bargaining power in Section 2.2: a decision to coordinate the chain changes the environment in which the parties operate and therefore may change their bargaining power. Note that this explanation is not purely theoretical. In application it is quite plausible that firms in a chain that agree to coordinate would still bargain over the wholesale price, e.g., due to uncertainties or different forecasts. The third explanation is that, different bargaining powers across manufacturers and retailers often exist in practice. For example, Draganska et al. (2010), show (Table 6) that among the seven manufacturers under investigation, Dallmayr yields the highest chain profit of 3.06 and highest manufacturer margin of 2.06. Dallmayr also has the highest bargaining power value of $\alpha=0.67$. Obviously, Dallmayr possesses an efficient bargaining power among its peers.

One of our main findings, which also dictates our definition of a coordinated chain, is that the bargaining power that would coordinate a chain depends on the contract space faced by the different firms. Thus, we first discuss this contract space. Next we characterize the actions of chains given these contracts. We then characterize this efficient bargaining power and compare the profits of chains with different bargaining power to this of the coordinated chain.

In the contract space, we consider a $\mathrm{BW}(\alpha)$ bargaining over the wholesale price with any 
$\alpha \in[0,1]$. Note that according to Theorem 1 both the VI and MS contracts are special cases of BW. Thus these common contracts are also included in the contract space. While there are potentially other contracts that can coordinate the chains in our industry, we focus on this contract space. Note that analyzing the equilibrium structure when both chains happen to have the efficient bargaining power, i.e., are coordinated, is sufficient for establishing our main results. Finding the best contract space in an industry with competition is an interesting and relevant question. However, this might require to address legal issues, e.g., anti-trust laws, and is outside the scope of this paper.

\subsection{The Nash Equilibrium for Efficient Bargaining Supply Chains}

To characterize the efficient bargaining power, we consider a game as follows: in the first stage a supply chain that "decides to coordinate itself" chooses the profit maximizing bargaining power to act with (this choice is done simultaneously if both supply chains are coordinating). This first stage is equivalent to finding a virtual chain with the profit maximizing bargaining power. We allow both chains to choose whether to coordinate themselves or not. Then, the next stages of the game continue as in the original game. That is, the manufacturer and retailer in each chain bargain over the wholesale price in accordance with their bargaining power (possibly the coordinating one) and then, retailers face a Bertrand competition in the market place.

The trick in the above game formulation is that the most efficient bargaining power would be the one that maximizes the chain's profit. As the equilibrium in the game is based on the best response i.e., the response that maximizes profit, the bargaining power "chosen" by the chain would be the efficient one. Thus, if a Nash equilibrium of this game exists, i.e., there is a best $\alpha$ to chose, this $\alpha$ maximizes the chains profit. For example, if the bargaining power chosen is with $\alpha=0$, then the VI response is the one that maximizes the chain's profit, i.e., VI coordinates the chain. Theorem 2 below establishes the unique subgame perfect Nash equilibrium when both supply chains are efficient.

Theorem 2. The efficient bargaining power in the industry is given by the unique solution of the above defined game. Specifically, if each supply chain can agree on $\alpha \in[0,1]$ to coordinate 
itself, the unique Nash equilibrium for the strategic choices of both supply chains is given by:

$$
\begin{array}{lc}
M S M S & \text { for }|b| \in[\bar{b}, 1] \\
B W\left(\alpha^{*}(b)\right) B W\left(\alpha^{*}(b)\right) & \text { for }|b| \in(0, \bar{b}) \\
V I V I & \text { for } b=0,
\end{array}
$$

where $\bar{b} \approx 0.966$ and

$$
\alpha^{*}(b)=\frac{2\left(b^{2}-2\right)}{b^{4}}\left(3 b^{2}-4-\left(b^{2}-4\right) \sqrt{1-b^{2}}\right) .
$$

If the bargaining power in the $j^{\text {th }}$ supply chain is given, i.e., $\alpha_{j}$ is known, the efficient bargaining power for the $i^{\text {th }}$ chain is

$$
\alpha_{i}^{*}(b)=\min \left\{\frac{4 b^{2}\left(b^{2}-2\right)\left(\alpha_{j}-\left(b^{2}-2\right)\right)}{b^{4} \alpha_{j}-8\left(b^{2}-2\right)^{2}}, 1\right\},
$$

where $\alpha_{j}=1$ (or 0 ) if the $j^{\text {th }}$ supply chain is MS (or VI), respectively.

In contrast to McGuire and Staelin (1983), we found that a unique NE exists for any $b \in[0,1]$, and more importantly that the VIVI structure is never an equilibrium in the industry (when $b=0$ the companies are not at the same industry). This contrast is because they ignore bargaining that includes a continuum of contracts. Such a continuum allows both parties to only slightly change their response, resulting in a unique best response. Under McGuire and Staelin (1983) setting the change in response was significant, e.g., moving from VI to MS (i.e. $\alpha=0$ to $\alpha=1$ ). This sharp change prevented the existence of the equilibrium in Theorem 2.

We emphasize that the manufacturer cannot just post the resulting wholesale price from a given bargaining power to improve the chain's performances (because the reaction functions of the parties in an MS contract are different). So the efficient supply chain structure depends on the competition and its operation including its bargaining power.

To demonstrate that simply posting the resulting wholesale price from Theorem 2 is not sufficient to maximize the chain's profit we next consider the most efficient MS contract. We obtain this efficient MS contract from a game where this contract coordinates the chains in our industry. In Section 5 of Cachon (2003) it is shown that a single manufacturer selling through several retailers can choose the wholesale price in an MS contract such that centralized profit (that of the coordinated VI chain) would be achieved. Here, we show that the MS contract can also coordinate competing chains in an industry. While the settings in 
our paper are different than in Cachon (2003), we consider competition between two chains, conceptually the idea is similar. We show that if for some reason the manufacturer wishes to choose the efficient wholesale price, i.e., the price that maximizes the chain's profit, she can do it while maintaining some positive profit.

The only contract considered here is the MS contract, which can be used to coordinate the chains. The sequence of events within each chain is the same as in the standard MS contract discussed in Section 1. Still, because the manufacturer can calculate the retailer's best response, the manufacturer can choose the wholesale price to coordinate the chain. In this case we have (to differentiate a non-coordinating contract from its coordinating version, we denote the latter contract with a superscript $\left.{ }^{*}\right)$ :

Theorem 3. If both supply chains use an $M S\left(w^{*}\right)$, choosing the wholesale price to coordinate themselves, there is a unique Nash Equilibrium where the wholesale price in both chains is:

$$
w^{*}(b)=\frac{b^{2}}{4-b^{2}-2 b}>0 .
$$

In the case discussed in Theroem 3 the best response $w^{*}(b)$ from (14) leads to the profit:

$$
\pi_{1}^{S C}\left(M S\left(w^{*}\right) M S\left(w^{*}\right)\right)=2 \frac{2-b^{2}}{\left(b^{2}+2 b-4\right)^{2}} .
$$

Thus, the standard wholesale price, take it or leave it contract, can be used to coordinate the chains in our model, while achieving positive profit for both parties in each chain. Theorem 3 further strengthens the second result highlighted by Theorem 2 - the VIVI structure, i.e., $w(b)=0$, is never optimal. Furthermore, Theorem 3 implies that when coordinating a supply chain in the presence of competition it is necessary to consider the detailed actions of the competition.

Returning to the results of Theorem 2 when both firms happen to have the efficient bargaining power, substituting $\alpha^{*}(b)$ from (12) into (20) (see Appendix I) gives the coordinating wholesale price:

$$
w\left(\alpha^{*}(b)\right)=\frac{4-3 b^{2}+\left(b^{2}-4\right) \sqrt{1-b^{2}}}{b\left(b^{2}+b-2-(b-2) \sqrt{1-b^{2}}\right)},
$$

which, differs from $w^{*}(b)$ given in (14), the one of an MS coordination mechanism. (This follows from the different reaction functions in both contracts.) Thus, we see that in our two supply chains industry, if $b \in(0, \bar{b})$ it is not enough to know that the other supply 
chain coordinates - but it is also necessary to know which coordination contract it uses. (Otherwise, both wholesale prices would be the same.)

To summarize, there are four insights from Theorems 2 and 3 . The first is that the benefit of the efficient bargaining power depends on the competition and the contract used by it. The second insight is that it is never equilibrium for the supply chain in the industry to VI (when $b=0$ the companies are not at the same industry). As explained before, this is in contrast to McGuire and Staelin (1983), where a VIVI structure is always equilibrium. The fact that the VIVI is never optimal in our model generalizes the results of Bonanno and Vickers (1988), by allowing complementary products (i.e., $b<0$ ) as well as substitutable ones. Moreover, the bargaining framework in Theorem 2 allows different bargaining powers and therefore profit division in the supply chain, whereas the two part tariff discussed in Bonanno and Vickers (1988) dictates that all profit goes to the manufacturer. The third insight is that if the manufacturer in a chain wishes to coordinate it, she can choose a wholesale price that is strictly higher than cost. Such a price implies not only that the profit of the manufacturer is positive but also that the coordinated chain is not VI. The fourth insight is that coordination in the industry should consider the competition and the contract used by it. This highlights the difficulty of coordinating supply chains in practice, when chains are typically not monopolistic.

\subsection{The Advantages from a Favorable Bargaining Structure}

Here we investigate the benefit of chains with favorable bargaining power (i.e., a bargaining power that is closer to the efficient one) over a chain with a less favorable bargaining power, even if the chains are not coordinated. To achieve this we consider the efficient bargaining power as a benchmark for the effectiveness of other bargaining power. We then consider the case where both chains operate with the efficient bargaining power. We consider a single chain that coordinates itself using the best response $\alpha_{i}^{*}(b)$ from (13) in the range $|b| \leq \bar{b}$. This leads to the $i^{\text {th }}$ chain's profit $i=1,2, \alpha_{i}$ :

$$
\pi_{i}^{S C}\left(\frac{4 b^{2}\left(b^{2}-2\right)\left(\alpha_{j}-\left(b^{2}-2\right)\right)}{b^{4} \alpha_{j}-8\left(b^{2}-2\right)^{2}}, \alpha_{j}\right)=\frac{\left(4-2 b^{2}+b \alpha_{j}\right)^{2}(b+2)^{2}}{4\left(b^{2} \alpha_{j}-4 b^{2}+8\right)\left(2\left(b^{2}-2\right)^{2}-b^{2} \alpha_{j}\right)} .
$$




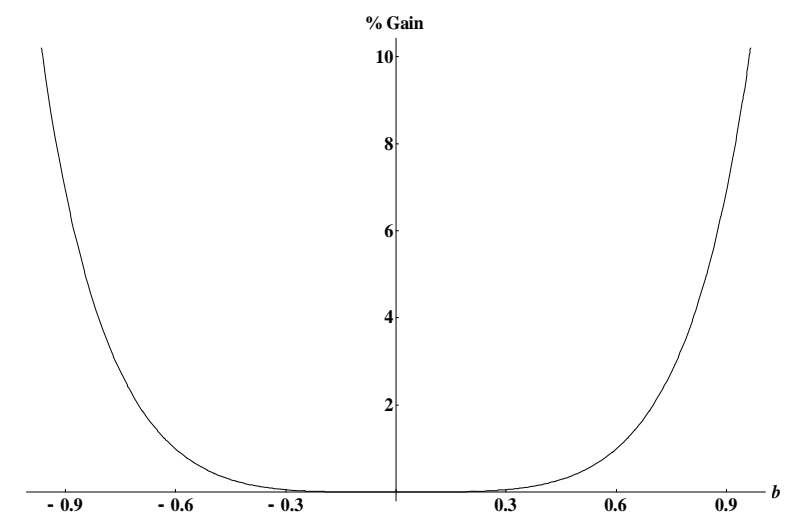

Figure 1: Percentage gains of the $i^{\text {th }}$ chain from using the efficient bargaining power, $\alpha_{i}=\alpha_{i}(b)$ from (13) rather than using a VI strategy, $\alpha_{i}=0$, when firm $j$ uses VI, $\alpha_{j}=0$.

Thus, the percentage gain from having the efficient bargaining power $\alpha_{i}$ is:

$$
\begin{gathered}
\frac{\pi_{i}^{S C}\left(\frac{4 b^{2}\left(b^{2}-2\right)\left(\alpha_{j}-\left(b^{2}-2\right)\right)}{b^{4} \alpha_{j}-8\left(b^{2}-2\right)^{2}}, \alpha_{j}\right)-\pi_{i}^{S C}\left(\alpha_{i}, \alpha_{j}\right)}{\pi_{i}^{S C}\left(\alpha_{i}, \alpha_{j}\right)}= \\
\frac{\left(4\left(b^{2}-2\right)\left(\left(b^{2}-2\right)\left(-b^{2}+2 \alpha_{i}\right)+b^{2} \alpha_{j}\right)-b^{4} \alpha_{i} \alpha_{j}^{2}\right)^{2}}{8\left(2-\alpha_{i}\right)\left(b^{2}-2\right)\left(2-b^{2}+\alpha_{i}\right)\left(b^{2} \alpha_{j}-2\left(b^{2}-2\right)^{2}\right)\left(b^{2} \alpha_{j}+4\left(2-b^{2}\right)\right)} .
\end{gathered}
$$

This percentage of profit lost can be substantial. For example, when both chains use $\alpha_{j}=\alpha_{i}=0.5$ rather than their best response, it can be verified that the percentage profits lost is maximized at almost $7 \%$ for $b=0$, i.e., when the best response for each chain is to VI. As another example, when $b=0.5$, and $\alpha_{j}=0.5$ it can be verified that if the $i^{\text {th }}$ supply chain uses an MS strategy more than $25 \%$ of its potential profit is lost. Both examples demonstrate that the benefit of a chain with a favorable bargaining power can be significant.

To highlight the ineffectiveness of a VI contract we consider the case where chain $j$ is VI and chain $i$ is also VI. Figure 1 depicts the percentage gains possible from having the efficient bargaining power as a function of $b \leq|\bar{b}|$. In this case the percentage gain from (18) becomes $b^{4} /\left(8\left(2-b^{2}\right)\right)$. It is seen that as $|b|$ is closer to $\bar{b}$ the benefit from coordinating symmetrically increases and it is maximized at about $10 \%$ when $|b|=\bar{b}$.

We next consider the case where both supply chains have the equilibrium bargaining power in the industry. This can be caused for example by either one of the explanations in Section 5. Note that due to the uniqueness of the Nash equilibrium in Theorem 2, only symmetric strategies can be a Nash equilibrium in this setting. 
(a)

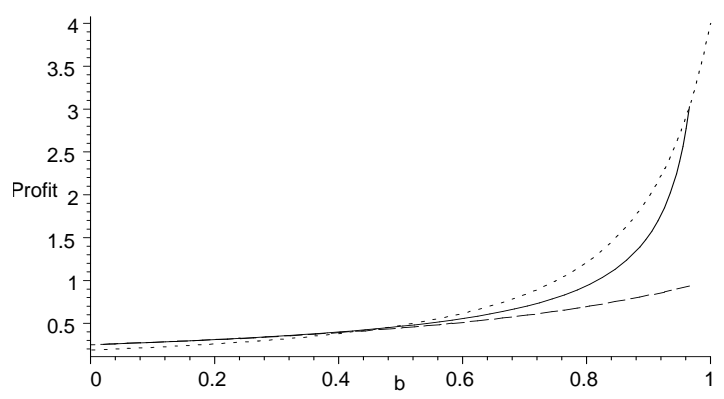

(b)

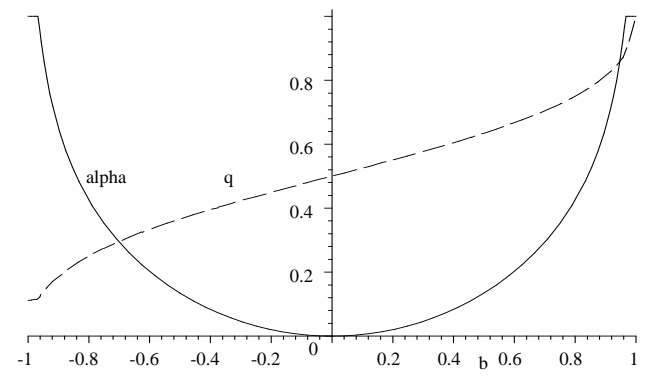

Figure 2: Part (a) $\pi_{i}^{S C}(B W B W)$ (solid), $\pi_{i}^{S C}(M S M S)$ (dash), $\pi_{i}^{S C}(V I V I)$ (dots) for $b \in(0,1)$. Part (b) $\alpha$ (solid) $q$ (dash) for $b \in(-1,1)$.

When both chains have the coordinating bargaining power, i.e., the best response $\alpha^{*}(b)$ in the range $|b| \leq \bar{b}$ (given in (27), in Appendix I), they would have the following chains' profits:

$$
\pi_{i}^{S C}\left(B W\left(\alpha^{*}\right) B W\left(\alpha^{*}\right)\right)=\frac{\left(b^{2}-(b+2)\left(1-\sqrt{1-b^{2}}\right)\right)^{2}}{4 b^{2}\left(b^{2}+\sqrt{1-b^{2}}-1\right)\left(1-\sqrt{1-b^{2}}\right)} .
$$

Figure 2(a) illustrates respectively $\pi_{i}^{S C}\left(B W\left(\alpha_{1}^{*}(b)\right) B W\left(\alpha_{2}^{*}(b)\right)\right), \pi_{i}^{S C}(M S M S)$ and $\pi_{i}^{S C}(V I V I)$ as functions of $b \in(0,1)$. While, as can be seen $B W\left(\alpha_{1}^{*}(b)\right) B W\left(\alpha_{2}^{*}(b)\right)$ may yield lower profit than the $M S M S$ result, the $M S M S$ is not equilibrium, i.e., the chains can improve profitability by deviating from this result. That is if both chains are $M S$ and a chain that has a bargaining power $\alpha<1$ switches to bargaining over the wholesale price, it will improve its profitability. Thus, the $B W\left(\alpha_{1}^{*}(b)\right) B W\left(\alpha_{2}^{*}(b)\right)$ is the unique Nash equilibrium. This figure shows that the profit from coordinating the chain increases as competition intensifies. (This is true even after correcting for that the market size is increasing with $b$, as noted by Gupta and Loulou (1998).) In Figure 2 (b) we depict the equilibrium value of $\alpha$ and $q$ as functions of $b \in(-1,1)$. As expected when $b=0, \alpha=0$ (VIVI strategy) and when $|b|$ is close to $1, \alpha=1$ (MSMS strategy). In addition $q$ is increasing in $b$ as the market size of the example expands.

\subsection{Comparison with Empirical Studies and Discussion}

Here, we contrast the findings from our stylized theoretical model with some of the empirical observations in Slade (1998), from the gasoline industry in Vancouver and in Draganska et al. (2010) from the German coffee market. 
Theorem 2 predicts that in equilibrium the manufacturer bargaining power increases with competition and that the MS contract maximizes profit when competition is more intense. Indeed, this is observed in practice. Consider the gasoline industry in the city of Vancouver whose setting fits the one considered in our paper. The major oil companies sell their oil directly to the end consumer under their brand name. These companies control about $88 \%$ of the market. Slade (1998) shows that gas stations facing a more intense competition (measured by a relatively lower own price elasticity and higher rivals' price elasticity) often set their retail price independently, demonstrating a higher vertical separation that is aligned with a higher manufacturer bargaining power. Moreover, Slade (1998) shows that in such gas stations the potential improvement in profit from using an MS contract is higher.

Draganska et al. (2010) consider the German coffee market where several retailers and manufacturers are competing. They assume that the bargaining within each manufacturer and retailer are over the wholesale price and occur within one supply chain at a time. This suggests that our results from Theorem 2 would provide a reasonable explanation to the end results in this market.

The discussion at the end of section 5.1 highlights that a VI contract never maximizes the chains' profit within an industry with competition. That is in the German coffee industry we would expect that chains working in a structure closer to VI gain less profit. Given the results of Theorem 1 VI contract is equivalent to a manufacturer bargaining power $\alpha=0$; thus we expect that as the bargaining power of the manufacturer is closer to 0 and that of the retailer is closer to 1 , the profits of the chain will decrease. Indeed, looking at Tables 6 and 7 in Draganska et al. (2010) we observe that the manufacturer Melitta, that has the lowest bargaining power $\alpha=0.41$, results in the lowest chain's margin of 1.77; similarly, the retailer Markant, that has the highest bargaining power $1-\alpha=0.53$, results in the lowest chain's margin of 2.07.

To further investigate this industry, we observe from Table 6 in Draganska et al. (2010), that the average manufacturer bargaining power in this table is $\alpha=0.557$. The manufacturer Dallmayr yields the highest chain's profit and has a bargaining power of $\alpha=0.67$. Assuming that $\alpha=0.67$ is the coordinated bargaining power given in (12), we can solve for the implied substitution level, $b$, in our theoretical model. The resulted $b$ is $b=0.93$ (the other solution, $b=-.93$, is not relevant here). Alternatively, from table 7 the average retailer bargaining power is $1-\alpha=.553$ (very similar to the average manufacturer bargaining power calculated 
from Table 6). The retailer Spar, with a bargaining power of $1-\alpha=.38$ yields the highest chain's profit, i.e., $\alpha=0.62$. Assuming that this $\alpha$ value maximizes the chain's profit, as in (12), the implied substitution level in our theoretical model is $b=0.9$. Both ways to estimate $b$ imply quite an intense competition in this market; while the predicted $b$ values are high they are still below $\bar{b}=0.966$, where MS becomes the coordinated contract.

One can further interpret these results: given the average bargaining power and the intense competition in this industry a bargaining power of $\alpha=0.67$ would be close to the optimal one. Indeed, from Table 6 of Draganska et al. (2010) both Idee and Tchibo, with the second highest bargaining power of $\alpha=0.66$, also have the second highest manufacturers' and chains' margins. Moreover, manufacturers with weaker bargaining power have both lower manufacturers' and chains' margins.

To further support our discussion, from Table 7 of Draganska et al. (2010) we observe that Tengelm, with a bargaining power of $1-\alpha=0.42$, which is the second closest to the coordinated $1-\alpha$, also has the second highest chain margins and that as the other retailers' bargaining power further increases, their total chains margin decrease.

Finally, from our model, in an industry with $b=0.93$ or $b=0.9$, the equilibrium profit maximizing bargaining power, from (12) is $\alpha(0.93)=0.77$ or $\alpha^{*}(0.9)=0.65$; thus, our predictions are that a manufacturer power around $\alpha \approx 0.7$ in this industry would further benefit the total profits of all chains (the size of the pie). That is we predict that retailers average bargaining power in this highly competitive industry should decrease with time. It would be interesting to see if since the data in Draganska et al. (2010) was collected, a shift in the bargaining powers of additional participants in the industry towards $\alpha \approx 0.7$ has occured.

To summarize, the insights from this section are threefold. First, the benefit of having the best, efficient, bargaining power may be substantial. Second, in contrast to the common belief in the operations management literature, not just that a VI chain is not coordinated - such a contract may leave much profit on the table. The third insight is that even if competing chains happen to be coordinated (i.e., having the efficient bargaining power), there may still be money left on the table (comparing to the $M S M S$ strategies). This loss of profit is due to the effect of competition. Furthermore, we discussed empirical evidence that further supports the theoretical results from our stylized model and these insights. 


\section{Summary and Future Research}

In this paper we first considered bargaining over the wholesale price (BW) within a single chain. With extreme bargaining powers, the bargaining over the wholesale model is equivalent to the standard MS or VI. (See Theorem 1). Next, we studied the BW strategy with an asymmetric bargaining power within a chain. We investigated the influence of the bargaining power within a chain on its industry. We further identified the unique equilibrium power structure within the chains. Thus, in mature industries, our theory predicts that when the competition is more intense ( $b$ is higher), the equilibrium contract from Theorem 2 in each chain will have a higher manufacturer power $(\alpha)$. As mentioned before, these predictions are in line with the empirical findings in Slade (1998). Other predictions from the model on the coordinating bargaining power and the effect of diverting from it on the chains profit agree with the empirical findings in Draganska et al. (2010). We further establishd that it is never equilibrium for both supply chains in the industry to vertically integrate. Thus, a VI chain is not coordinating in this setting. This result contrasts a large stream of literature suggesting supply chains coordination contracts that induce chains to act as if they are VI. Supply chains that are a part of an oligopoly and use such contracts are not really coordinated - they leave money on the table. This prediction is in line with the empirical findings in Slade (1998).

Our results for the case when both supply chain compete assume that (i) information is common knowledge, (ii) both supply chains act at the same time, i.e., neither one of them is a leader, (iii) while bargaining over the wholesale price the firms use a zero threat point, and (iv) that each retailer sells only a single product. While the specific equilibrium may change without these assumptions, the main insights mentioned above seem to be independent of these assumptions. For example, VI will still not be an equilibrium that maximizes the chains' profits and the VIVI structure would not coordinate the chains. Similarly, there will probably be a most efficient bargaining power that maximizes the chains profit.

The results of this paper enrich the understanding of the effects that competition and bargaining have on strategical supply chain management. Furthermore, we hope that our models can provide a framework for future models for applicable supply chain contracts that can improve profit in the presence of competition and negotiation and for empirical work studying the effect of bargaining power within a supply chain.

We suggest several directions for future research. The first is to relax the assumptions 
mentioned above, e.g., to consider uncertainties (Choi et al., 2008). The second is to search for an optimal contract space for coordinating chains in the presence of competition. For example, it is interesting to characterize contracts that would allow chains with a specific bargaining power to act in accordance with the efficient (coordinating) power. As the discussion in Section 3 suggests, direct bargaining over profit sharing may not be helpful in achieving this (because it induces the chains to act as VI). The third is to generalize our approach for more realistic settings, e.g., retailers facing an uncertain demand or information asymmetry. An initial consideration of uncertain demand is given in Wu et al. (2009). The fourth direction is to empirically investigate the benefit of chains with favorable bargaining power over chains with a less favorable bargaining power and the dependence of this benefit on the level of competition in the market. This would be similar to the study in Draganska et al. (2010).

Acknowledgment: We thank the anonymous review team for suggestion that improved the paper significantly. This paper was supported by NSERC grants of the first two authors.

\section{References}

Balasubramanian, S., P. Bhardwaj. (2004). When not all conflict is bad: Manufacturingmarketing conflict and strategic incentive design. Management Science, 50(40), 489-502.

Bernstein, F., A. Federgruen. (2005). Decentralized supply chains with competing retailers under demand uncertainty. Management Science, 51(1), 18-29.

Binmore, K., A. Rubinstein, A. Wolinsky. (1986). The Nash bargaining solution in economic modelling. RAND Journal of Economics, 17, 176-188.

Bonanno, G. , J. Vickers. (1988). Vertical separation. J. Indust. Econom., 36, 257-265.

Cachon, G. (2003). Supply chain coordination with contracts. Handbooks in Operations Research and Management Science: Supply Chain Management. Edited by Steve Graves and Ton de Kok. North Holland, 229-340.

Cachon, G. P., M. Lariviere. (2005). Supply chain coordination with revenue sharing contracts. Management Science, 51(1), 30-44.

Cachon, G. P., S. Netessine. (2004). Game theory in supply chain analysis. Chapter 2 in Handbook of Quantitative Supply Chain Analysis: Modeling in the E-Business Era, edited by D. Simchi-Levi, S. D. Wu and M. Shen, Kluwer, New-York.

Choi T. M., D. Li, and Yan H., "Mean-variance analysis for the newsvendor problem," IEEE 
Transactions on Systems, Man, and Cybernetics Part A, vol. 38, no. 5, pp. 1169-1180, 2008.

Coughlan, A.T. (1985). Competition and cooperation in marketing channel choice: Theory and application. Marketing Science, 4(Spring), 110-129.

Coughlan, A.T., B. Wernerfelt. (1989). On credible delegation by oligopolists: a discussion of distribution channel management. Management Science, 35(2), 226-239.

Draganska, M., D. Klapper, and S. B. Villas-Boas (2010). A larger slice or a larger pie? An empirical investigation of bargaining power in the distribution channel. Marketing Science $29(1), 57-74$.

Dukes, A. J., E. Gal-Or, S. Kannan. (2006). Channel bargaining with retailer asymmetry. Journal of Marketing Research, XLIII (February 2006), 84-97.

Ertek G., P. M. Griffin. (2002). Supplier- and buyer-driven channels in a two-stage supply chain. IIE Transactions, 34, 691-700.

Feng, Q., L. X. Lu (2012). The strategic perils of low cost outsourcing. Management Science, 58 (6), 1196-1210.

Gupta, S., R. Loulou. (1998). Process innovation, product differentiation and channel structure: strategic incentives in a doupoly. Marketing Science, 4, 301-316.

Gurnani, H., M. Shi. (2006). A bargaining model for a first-time interaction under asymmetric beliefs of supply reliability. Management Science, 52(6), 865-880.

Ingene, C.A., M.E. Parry. (1995). Channel coordination when retailers compete. Marketing Science, 14(4) 360-377.

Iyer, G., J. M.Villas-Boas. (2003), A bargaining theory of distribution channels. Journal of Marketing Research, XL, 80-100.

Kalai, E., D. Smordinsky. (1975). Other solutions to Nash's bargaining problem. Econometrica, 43, 513-518.

Lariviere, M.A. , E.L. Porteus. (2001). Selling to the newsvendor: An analysis of price-only contracts. Manufacturing and Service Operations Management, 3(4), 293-305.

Lin, R. Y., L. Z. Kong. (2002). The impact of channel power of symmetric competing channels on the profit segmentation. Proceeding of National Conference of Chinese National Academy, December 21.

Liu, Y., and R. K. Tyagi (2011). The benefits of competitive upward channel decentralization. Management Science, 57(4), 741-751. 
McGuire, T. W., R. Staelin. (1983). An industry equilibrium analysis of downstream vertical integration. Marketing Science, 2(2), 161-191.

Mills, E. S. (1959). Uncertainty and price theory. Quarterly J. Economics, 73, 116 -130.

Misra, S. and Mohanty, S. (2006). Estimating bargaining games in distribution channels, working paper, University of Rochester.

Moorthy, K. (1988). Strategic decentralization in channels. Marketing Science, 7(4), 335355.

Nagarajan, M., Y. Bassok. (2008). A bargaining framework in supply chain-the assembly problem. Management Science, 54(8), 1482-1496.

Nagarajan, M., G. Sosic. (2008). Game theoretical analysis of cooperation among supply chain agents: review \& extensions. European Journal of Operational Research, 187.

Nair, A., R. Narasimhan and E. Bendoly. (2011). Competitive buyer-supplier relationship: An investigation of bargaining power, relational context, and investment strategies. Decision Sciences 42(1): 93-127.

Nash, J. F. (1950). The bargaining problem. Econometrica, 18, 155-162.

Pasternack, B.A. (1985). Optimal pricing and returns policies for perishable commodities. Marketing Science, 4(2), 166-176.

Shen B., Choi T. M., Wang Y., and Lo C. K. L. (2013). The coordination of fashion supply chains with a risk averse supplier under the markdown money policy, IEEE Transactions on Systems, Man, and Cybernetics, Part A. 43(2), 266 - 276.

Slade, M.E. (1998). Strategic motives for vertical separation: evidence from retail gasoline markets. Journal of Law, Economics and Organization, 14, 84-113.

Staelin, R. (2008). Commentary - An industry equilibrium analysis of downstream vertical integration: tweenty-five years later. Marketing Science, 27(1), 111. doi:10.1287/mksc.1070.0340.

Tsay, A. (1999). Quantity-flexibility contract and supplier-customer incentives. Management Science, 45(10), 1339-1358.

Weng, Z. K. (1995). Channel coordination and quantity discounts. Management Science, 41( 9), 1509-1522.

Wu D., O. Baron, O. Berman. (2009). Bargaining in competing supply chains with uncertainty. European Journal of Operational Research, 197, 548-556.

Wu, D., H. Chen. (2003). Chain-to-chain competition under demand uncertainty. Working paper. University of Michigan. 


\section{Appendix I: Proofs}

\section{Solutions for bargaining on the wholesale price in the Industry (from Section 4)}

It can be verified that the solution to the best response functions of both chains is

$$
w_{i}=\alpha_{i} \frac{(b+2)\left(2 b^{2}-b \alpha_{j}-4\right)}{\alpha_{i} b^{2} \alpha_{j}-4\left(b^{2}-2\right)^{2}} \quad i=1,2 \quad j=3-i .
$$

Thus, the optimal supply chain profit when both supply chains use a $\mathrm{BW}\left(\alpha_{i}\right) \mathrm{BW}\left(\alpha_{j}\right)$ contract is (with $i=1,2$ and $j=3-i$ ):

$$
\begin{aligned}
\pi_{i}^{S C}\left(\alpha_{i}, \alpha_{j}\right)= & \frac{2\left(b^{2}-2\right)\left(2\left(b^{2}-2\right)\left(2-\alpha_{i}\right)+b \alpha_{j}\left(\alpha_{i}-2\right)\right)}{(2-b)^{2}} \\
& * \frac{\left(\left(b^{2}-2\right)\left(2\left(b^{2}-2\right)-b \alpha_{j}-2 \alpha_{i}\right)+\alpha_{i} b \alpha_{j}\right)}{\left(\alpha_{i} b^{2} \alpha_{j}-4\left(b^{2}-2\right)^{2}\right)^{2}}
\end{aligned}
$$

Using Proposition 1, when both chains use either a VI or an MS strategy we can use the results of the $B W(0)$ or $B W(1)$ models, respectively, to obtain the results of McGuire and Staelin (1983) for these cases.

We further observe that

$$
\pi^{M}=q_{i} w_{i}=\frac{2(b+2)\left(b^{2}-2-\alpha_{i}\right)\left(2 b^{2}-b \alpha_{j}-4\right)^{2} \alpha_{i}}{(b-2)\left(4\left(b^{2}-2\right)^{2}-\alpha_{i} b^{2} \alpha_{j}\right)^{2}},
$$

which, as expected, is increasing with $\alpha_{i}$ - the manufacturer's bargaining power.

Proof of Theorem 1: When $\alpha=1$, the manufacturer chooses the wholesale price without considerations for the retailer's profits - just as in the MS model, establishing the equivalence between the MS and $B W(1)$ models. For the case $\alpha=0$ we have

$$
\begin{aligned}
\frac{d \Phi(w)}{d w} & =\frac{\partial \Phi(w)}{\partial w}+\frac{\partial \Phi(w)}{\partial p} \frac{d p}{d w}=\frac{\partial \pi^{R}}{\partial w}+\frac{\partial \pi^{R}}{\partial p} \frac{d p}{d w} \\
& =\frac{\partial \pi^{R}}{\partial w}=\frac{\partial \Phi(w)}{\partial w}=-q \leq 0
\end{aligned}
$$

where $\Phi(w)=\pi^{R}$ in the second equality because $\alpha=0$, the third equality is an application of the Envelope Theorem, which we use because $p$ is chosen to maximize the retailer's profit. Thus, for $\alpha=0, \Phi(w)$ is non-increasing with $w$ and the choice $w=0$ maximizes $\Phi(w)$. Observing that $\Phi(0)=\pi^{S C}$, the retailer's next choice for $p$ (and $q$ ) maximizes $\pi^{R}=\pi^{S C}$ as does a VI chain.

Proof of Theorem 2: The equivalence of the efficient bargaining power and the one chosen in this game follows from the discussion above the Theorem. Taking the first order conditions 
with respect to $\alpha_{i}$ in (21) leads to the best response function (second order conditions can be verified to result in a maximum):

$$
\bar{\alpha}_{i}^{*}(b)=\frac{4 b^{2}\left(b^{2}-2\right)\left(\alpha_{j}-\left(b^{2}-2\right)\right)}{b^{4} \alpha_{j}-8\left(b^{2}-2\right)^{2}} .
$$

It is easily verified that $\bar{\alpha}_{i}^{*}$ is increasing with $\alpha_{j}$ (strictly increasing for every $b \neq 0$ ). Also, $\bar{\alpha}_{i}^{*}(0)=0$ establishing the non surprising optimality of a VIVI structure when the supply chains are monopolistic, i.e., for $b=0$ and (13). For $b \neq 0$ we use that both chains are symmetric and solve

$$
\alpha_{i}(b)=\frac{4 b^{2}\left(b^{2}-2\right)\left(\alpha_{i}(b)-\left(b^{2}-2\right)\right)}{b^{4} \alpha_{i}(b)-8\left(b^{2}-2\right)^{2}}
$$

to get two solutions. One of them leads to $\alpha_{i}$ larger than 1 , and the second one is given in (12). Thus, whenever $\bar{\alpha}^{*}(b)$ as given in $(12)$ holds $\bar{\alpha}^{*}(b) \in[0,1]$, it is a Nash Equilibrium. We now observe that $\bar{\alpha}^{*}(b)$ is increasing with $b$. Thus, for any $b$ smaller than $\arg \left\{\frac{2\left(b^{2}-2\right)}{b^{4}}\left(3 b^{2}-4-\left(b^{2}-4\right) \sqrt{1-b^{2}}\right)=1\right\} \equiv \bar{b} \approx 0.96613$ we have $\bar{\alpha}^{*}(b) \leq 1$. Finally, because $\bar{\alpha}_{i}^{*}(b)$ is strictly increasing with $\alpha_{j}$, for any $b \geq \bar{b}$ the best response of both chains is setting $\alpha^{*}(b)=1$ that is identical to an $M S M S$ structure. Thus, the best response function is

$$
\alpha_{i}^{*}(b)=\left\{\begin{array}{cc}
\frac{4 b^{2}\left(b^{2}-2\right)\left(\alpha_{j}-\left(b^{2}-2\right)\right)}{b^{4} \alpha_{j}-8\left(b^{2}-2\right)^{2}} & b<|\bar{b}| \\
1 & |\bar{b}| \leq b \leq 1
\end{array} \quad \forall \alpha_{j} \in[0,1] \quad j=3-i .\right.
$$

To show the uniqueness of this Nash equilibrium we use a contraction mapping argument. Based on Definition 4 and Theorem 4 of Cachon and Netessine (2004), it suffices to show that the best response functions in (27) are contraction mapping; i.e., that

$$
\left|\frac{d \alpha_{i}^{*}(b)}{d \alpha_{j}}\right|<1 \quad i=1,2, \quad j=3-i, \quad \forall b \in(-1,1) \quad \alpha_{j} \in[0,1] .
$$

We observe that the best response for $b>|\bar{b}|$ is fixed and clearly satisfies (28). To verify (28) for $b<|\bar{b}|$ we observe that for $i=1,2, j=3-i, \quad \forall b \in(-1,1) \quad \alpha_{j} \in[0,1]$ :

$$
\begin{aligned}
& \frac{d^{2} \alpha_{i}^{*}(b)}{d\left(\alpha_{j}\right)^{2}}=-\frac{8 b^{6}\left(b^{2}-2\right)^{2}\left(b^{2}-4\right)^{2}}{\left(b^{4} \alpha_{j}-8 b^{4}+32 b^{2}-32\right)^{3}} \geq 0 \\
& \frac{d^{2} \alpha_{i}^{*}(b)}{d \alpha_{j} d b}=-8 b \frac{\alpha_{j}\left(\left(b^{2}-2\right)\left(b^{6}+2 b^{4}-16 b^{2}+32\right)-2 b^{4} \alpha_{j}\right)-8\left(b^{2}-2\right)^{4}}{\left(b^{4} \alpha_{j}-8 b^{4}+32 b^{2}-32\right)^{2}} \geq 0 .
\end{aligned}
$$

Thus, $\frac{d \alpha_{i}^{*}(b)}{d \alpha_{j}}$ is increasing with $\alpha_{j}$ and with $|b|$ and it suffices to show that

$$
\left.\frac{d \alpha_{i}^{*}(b)}{d \alpha_{j}}\right|_{\alpha_{j}=1,|b|=1}<1, \quad i=1,2, \quad j=3-i,
$$


which follows from

$$
\begin{aligned}
\left.\frac{d \alpha_{i}^{*}(b)}{d \alpha_{j}}\right|_{\alpha_{j}=1,|b|=1} & =\left.\left|\frac{4 b^{2}\left(b^{2}-2\right)^{2}\left(b^{2}-4\right)^{2}}{\left(\alpha_{j} b^{4}-8 b^{4}+32 b^{2}-32\right)^{2}}\right|\right|_{\alpha_{j}=1,|b|=1} \\
& =\left.\frac{4 b^{2}\left(b^{2}-2\right)^{2}\left(b^{2}-4\right)^{2}}{\left(b^{4}-8 b^{4}+32 b^{2}-32\right)^{2}}\right|_{|b|=1}=\left(\frac{6}{7}\right)^{2} \quad i=1,2, \quad j=3-i,
\end{aligned}
$$

concluding the proof.

Proof of Theorem 3: It can be verified that the choices of prices and quantities for both supply chains will be identical to those in (9) and (10), respectively. This leads to a supply chain profit of

$$
\pi_{i}^{S C}\left(w_{i}, w_{j}\right)=q_{i} p_{i}=\left(2+b+b w_{j}+w_{i} b^{2}-2 w_{i}\right) \frac{2+b+b w_{j}+2 w_{i}}{\left(b^{2}-4\right)^{2}} .
$$

Taking the first order conditions with respect to $w_{i}$ of (33) leads to the best response functions (second order conditions can be verified to result in a maximum):

$$
w_{i}\left(b, w_{j}\right)=\frac{b^{2}}{4} \frac{2+b+b w_{j}}{2-b^{2}}
$$

This $w_{i}\left(b, w_{j}\right)$ is increasing with $w_{j}$ (strictly increasing for every $\left.b \neq 0\right)$. Also, $w_{i}\left(0, w_{j}\right)=0$ is the wholesale price that coordinates monopolies (i.e., is identical to a VI supply chain). For $b \neq 0$ we solve the two reaction functions to get:

$$
w_{i}^{*}(b)=\frac{b^{2}}{4-b^{2}-2 b} .
$$

To show the uniqueness of this Nash equilibrium as in the proof of Theorem 2, it suffices to show that the best response functions in (34) are contraction mappings, i.e., that

$$
\left|\frac{d w_{i}\left(b, w_{j}\right)}{d w_{j}}\right|<1 \quad i=1,2, \quad j=3-i, \quad \forall b \in(-1,1) .
$$

To verify (36) we observe that

$$
\begin{aligned}
\frac{d w_{i}\left(b, w_{j}\right)}{d w_{j}} & =\frac{1}{4} \frac{b^{3}}{b^{2}-2} \\
\frac{d^{2} w_{i}\left(b, w_{j}\right)}{d b d w_{j}} & =\frac{1}{4} b^{2} \frac{6-b^{2}}{\left(b^{2}-2\right)^{2}} .
\end{aligned}
$$

Thus, $\frac{d w_{i}\left(b, w_{j}\right)}{d w_{j}}$ is increasing with $b \in[-1,1]$ (strictly increasing $\forall b \neq 0$ ) and it suffices to show that

$$
\left.\frac{d w_{i}\left(b, w_{j}\right)}{d w_{j}}\right|_{|b|=1}<1, \quad i=1,2, \quad j=3-i
$$


which follows from

$$
\begin{gathered}
\left.\frac{d w_{i}\left(b, w_{j}\right)}{d w_{j}}\right|_{b=1}=-\frac{1}{4} \\
\left.\frac{d w_{i}\left(b, w_{j}\right)}{d w_{j}}\right|_{b=-1}=\frac{1}{4}
\end{gathered}
$$

concluding the proof. 